Article

\title{
Experimental Realization of Heavily p-doped Half-Heusler CoVSn Compound
}

\author{
Sadeq Hooshmand Zaferani ${ }^{1,2, *}$, Alireza Darebaghi ${ }^{1}$, Soon-Jik Hong ${ }^{3}$, Daryoosh Vashaee ${ }^{2,4, *(1)}$ \\ and Reza Ghomashchi 1,5,6,* \\ 1 School of Mechanical Engineering, University of Adelaide, Adelaide, SA 5005, Australia; \\ alireza.darebaghi@adelaide.edu.au \\ 2 Department of Electrical and Computer Engineering, North Carolina State University, Raleigh, \\ NC 27606, USA \\ 3 Division of Advanced Materials Engineering, Kongju National University, Chungnam 331-717, Korea; \\ hongsj@kongju.ac.kr \\ 4 Department of Materials Science and Engineering, North Carolina State University, Raleigh, NC 27606, USA \\ 5 ARC Research Hub for Graphene Enabled Industry Transformation, University of Adelaide, \\ Adelaide, SA 5005, Australia \\ 6 Institute For Photonics And Advanced Sensing, University of Adelaide, Adelaide, SA 5005, Australia \\ * Correspondence: sadeq.hooshmandzaferani@adelaide.edu.au (S.H.Z.); dvashae@ncsu.edu (D.V.); \\ reza.ghomashchi@adelaide.edu.au (R.G.)
}

Received: 24 February 2020; Accepted: 19 March 2020; Published: 20 March 2020

check for updates

\begin{abstract}
Hypothetical half-Heusler $(\mathrm{HH})$ ternary alloy of CoVSn has already been computationally investigated for possible spintronics and thermoelectric applications. We report the experimental realization of this compound and the characterizations of its thermoelectric properties. The material was synthesized by a solid-state reaction of the stoichiometric amounts of the elements via powder metallurgy ( $30 \mathrm{~h}$ mechanical milling and annealing at $900^{\circ} \mathrm{C}$ for $20 \mathrm{~h}$ ) and spark plasma sintering (SPS). The temperature-dependent ternary thermodynamic phase diagram of Co-V-Sn was further calculated. The phase diagram and detailed analysis of the synthesized material revealed the formation of the non-stoichiometry $\mathrm{HH} \mathrm{CoVSn}$, mixed with the binary intermetallic phases of $\mathrm{SnV}_{3}, \mathrm{Co}_{2} \mathrm{Sn}$, and $\mathrm{Co}_{3} \mathrm{~V}$. The combination of X-ray diffraction, energy-dispersive $\mathrm{X}$-ray spectroscopy, and thermoelectric transport properties confirmed the formation of a multi-phase compound. The analysis revealed the predicted thermoelectric features $(\mathrm{zT}=0.53$ ) of the highly doped CoVSn to be compromised by the formation of intermetallic phases $(\mathrm{zT} \approx 0.007)$ during synthesis. The additional phases changed the properties from $\mathrm{p}$ - to overall n-type thermoelectric characteristics.
\end{abstract}

Keywords: half-Heusler; CoVSn; thermoelectric; heterogeneous structure

\section{Introduction}

There have been substantial progress in thermoelectric (TE) materials over the last two decades. Thermoelectric technology, which was mainly based on alloys of bismuth telluride [1] for Peltier cooling modules, or silicon-germanium alloys [2] for radioisotope thermoelectric generators used in NASA spacecraft, has expanded to new compounds for power generation and cooling [3]. New materials and material structures have been discovered with considerably enhanced thermoelectric properties [4]. In particular, some materials like half-Heusler $(\mathrm{HH})$ alloys have shown an inherently large thermoelectric power factor, although they have generally higher thermal conductivity than alloys such as Skutterudites [5] and Clathrates [6]. Since the thermal conductivity can be decreased by structural engineering, their potential to provide inherently significant power factors has attracted much attention lately. Recently, a new class of $\mathrm{HH}$ compounds was predicted with low thermal 
conductivity [7]. In this regard, the sheer number of $\mathrm{HH}$ compounds to investigate is vast, and computational and predictive methods to shortlist the promising ones have become essential to making quick progress. First principle studies [8] and thermodynamic calculations [9] are some of the main methods to predict the new materials. Notably, HH alloys with the crystal structure of C1b (No. 216) and the atomic arrangement of XYZ [10] have attracted much attention due to their unusual TE characteristics, high-temperature stability, and doping capabilities (Figure 1, Table 1).

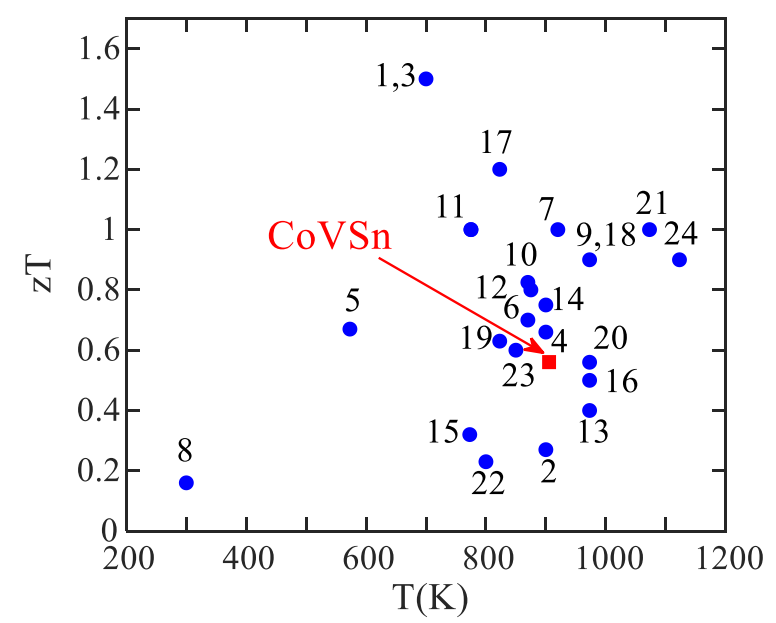

Figure 1. Selected alloys with their corresponding TE properties, which have been studied as half-Heusler (numbers are the items given in Table 1).

Table 1. Compounds cited in Figure 1.

\begin{tabular}{|c|c|c|c|c|c|}
\hline Item & Compound & Ref. & Item & Compound & Ref. \\
\hline 1 & $\mathrm{Ti}_{0.5}\left(\mathrm{Zr}_{0.5} \mathrm{Hf}_{0.5}\right)_{0.5} \mathrm{NiSn}_{0.998} \mathrm{Sb}_{0.002}$ & [11] & 13 & $\mathrm{NbCoSb}$ & [12] \\
\hline 2 & $\mathrm{TiCo}_{0.95} \mathrm{Ni}_{0.05} \mathrm{Sb}$ & [13] & 14 & $\mathrm{Zr}, \mathrm{Ni}, \mathrm{Sn}$ & [14] \\
\hline 3 & $\left(\mathrm{Zr}_{0.5} \mathrm{Hf}_{0.5}\right)_{0.5} \mathrm{Ti}_{0.5} \mathrm{NiSn}_{0.998} \mathrm{Sb}_{0.002}$ & [15] & 15 & $\mathrm{Ti}, \mathrm{Ni}, \mathrm{Sn}$ & [16] \\
\hline 4 & $\mathrm{Ti}_{0.5}(\mathrm{ZrHf})_{0.49} \mathrm{Nb}_{0.01} \mathrm{Ni}_{0.9} \mathrm{Pd}_{0.1} \mathrm{Sn}_{0.9} 8 \mathrm{Sb}_{0.02}$ & [17] & 16 & $\mathrm{VCoSb}$ & [18] \\
\hline 5 & $\mathrm{ZrNiSn}_{0.98} \mathrm{Sb}_{0.02}$ & [19] & 17 & $\mathrm{Ti}_{0.5} \mathrm{Zr}_{0.5} \mathrm{NiSn}_{0.98} \mathrm{Sb}_{0.02}$ & [20] \\
\hline 6 & $\left(\mathrm{Hf}_{0.6} \mathrm{Zr}_{0.4}\right)_{0.99} \mathrm{Y}_{0.01} \mathrm{NiSn}_{0.98} \mathrm{Sb}_{0.02}$ & [21] & 18 & $\left(\mathrm{Hf}_{0.25} \mathrm{Zr}_{0.75}\right)_{0.995} \mathrm{Nb}_{0.005} \mathrm{NiSn}$ & [22] \\
\hline 7 & $\mathrm{Hf}_{0.75} \mathrm{Zr}_{0.25} \mathrm{NiSn}_{0.99} \mathrm{Sb}_{0.01}$ & [23] & 19 & $(\mathrm{TiNiSn})_{0.95}+(\mathrm{MnNiSb})_{0.05}$ & [24] \\
\hline 8 & 1.5\% Y-Sb-doped Ti-Ni-Sn & [25] & 20 & $\mathrm{NbCoSb}_{0.8} \mathrm{Sn}_{0.2}$ & [26] \\
\hline 9 & $\mathrm{TiCoSb}_{0.8} \mathrm{Sn}_{0.2}$ & [27] & 21 & $\mathrm{Zr}_{0.5} \mathrm{Hf}_{0.5} \mathrm{Co}_{0.9} \mathrm{Ni}_{0.1} \mathrm{Sb}$ & [28] \\
\hline 10 & $\left(\mathrm{Zr}_{0.3} \mathrm{Hf}_{0.65} \mathrm{Ta}_{0.05}\right) \mathrm{NiSn}$ & [29] & 22 & $\mathrm{ZrCo}_{0.97} \mathrm{Pd}_{0.03} \mathrm{Bi}$ & [30] \\
\hline 11 & $\left(\mathrm{Ti}_{0.4}\left(\mathrm{Zr}_{0.5} \mathrm{Hf}_{0.5}\right)_{0.6}\right)_{0.99} \mathrm{Ta}_{0.01} \mathrm{NiSn}$ & [31] & 23 & $\mathrm{TiNi}_{1.06} \mathrm{Sn}_{0.81} \mathrm{Sb}_{0.17}$ & [32] \\
\hline 12 & $\mathrm{ZrNiSn}_{0.99} \mathrm{Sb}_{0.01}$ & [33] & 24 & $\mathrm{Nb}_{0.83} \mathrm{CoSb}$ & [34] \\
\hline \multicolumn{5}{|c|}{ Predicted TE factors of CoVSn compound, $\mathrm{K}=4.1 \mathrm{~W} / \mathrm{mK}, \mathrm{S}=175 \mu \mathrm{V} \mathrm{K}-1, \mathrm{zT}=0.53$ at $900 \mathrm{~K}$} & [35] \\
\hline
\end{tabular}

In 1995, Ögüt et al. [36] predicted CoVSn with a MgAgAs (C1b) crystal structure as an intermetallic semiconductor using density functional theory (DFT) band structure calculations. Another study [37] applied the full-potential linear muffin-tin orbital (FP-LMTO) method to evaluate the electronic properties of CoVSn alloy and showed an indirect energy bandgap of $0.75 \mathrm{eV}$. Shi et al. [38] calculated the electronic structure using the modified Becke-Johnson (MBJ) potential. Also, the transport coefficients were computed employing the Boltzmann theory within the constant scattering time approximation. Moreover, spin-orbit coupling (SOC) was considered in the electronic and transport calculations. Figure 2 shows the calculated electronic band structure and density of states (DOS) of CoVSn alloy [38]. Based on this electronic structure, the alloy was predicted as a p-type semiconductor with a bandgap (W-X) of $0.85 \mathrm{eV}$. 


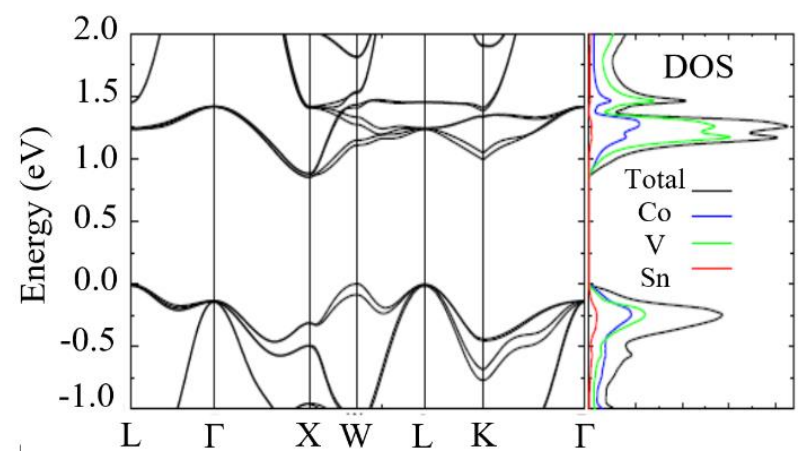

Figure 2. Calculated electronic band structure and density of states (DOS) of the CoVSn alloy. Reproduced from [38], Elsevier: 2017.

In the mentioned study, the maximum Seebeck coefficient with a carrier concentration of $1.0 \times 10^{21} \mathrm{~cm}^{-3}$ was calculated at a temperature of $1150 \mathrm{~K}$ as $340 \mu \mathrm{V} / \mathrm{K}$ [38]. Zeeshan et al. [39] carried out combined ab initio and semiclassical calculations based on Boltzmann transport theory and determined the maximum doping concentration of the p-type CoVSn alloy. Assuming a relaxation time of $10^{-15} \mathrm{~s}$ for $\mathrm{V}$ - and Cr-group doping, they estimated a Seebeck coefficient of $175 \mu \mathrm{V} / \mathrm{K}$ and a maximum power factor in the range of $11-23 \mu \mathrm{W} / \mathrm{K}^{-2}$ at optimum $0.26 \mathrm{e} / \mathrm{uc}$-type doping. This value of the power factor is comparable to the power factor of many good HH thermoelectric alloys.

Despite the wide range of theoretical studies on CoVSn alloy with predicted promising thermoelectric characteristics, to the best of our knowledge, there is no report on the thermoelectric characterization of a synthesized sample of this alloy in the open literature. The current study presents an experimental synthesis and characterization of the CoVSn compound, and an empirical thermoelectric and microstructure analysis is performed.

\section{Materials and Methods}

The powder mixture of CoVSn compound was prepared by ball milling (SPEX-6, Metuchen, NJ, USA) (5:1 ball-powder weights) a stoichiometric ratio (1:1:1) of Co, V and Sn elements (Alfa Aesar Co., $99.9 \%$ commercial purity, Ward Hill, MA, USA) for $30 \mathrm{~h}$ following an annealing process at $900{ }^{\circ} \mathrm{C}$ for $20 \mathrm{~h}$. The bulk samples were made by spark plasma sintering (SPS) at a temperature of $850{ }^{\circ} \mathrm{C}$ for $20 \mathrm{~min}$ at a pressure of $42 \mathrm{MPa}$. The phase identification was made via X-ray diffraction analysis (MiniFlex 300/600, 40 kV, 15 mA, Cu x-ray tube generation). The microstructure analysis was performed by field emission scanning electron microscopy (FESEM) (Quanta 450 FEG, FEI, Hillsboro, OR, USA). The thermal diffusivity $(v)$ was measured using a laser flash apparatus (LFA, Linseis, Selb, Germany) under an Ar environment from 30 to $550{ }^{\circ} \mathrm{C}$. The Archimedes method was used to measure the density of materials with deionized water (DI) water as a displacement medium. Also, the specific heat was approximated by the Debye specific heat [40] for a temperature range of 30 to $600{ }^{\circ} \mathrm{C}$. The electrical resistivity was measured using Linseis-LSR3 equipment (LSR3, Linseis, Selb, Germany) under He environment for the same temperature range. The Seebeck coefficient was measured simultaneously. The commercial Linsesis software calculates the thermopower from a single temperature gradient $(\Delta \mathrm{T})$ and voltage difference $(\Delta V)$, which is often erroneous. Therefore, the measurement was performed for five different temperature gradients, and each measurement was repeated four times, then averaged. The thermopower was calculated from the slope of the line fitted to five separate temperature and voltage differences. The accuracy of the measurement was verified by inspecting the linear fit to the $(\Delta \mathrm{T}-\Delta \mathrm{V})$ data set.

\section{Results and Discussion}

Figure 3 shows the X-ray diffraction data of the CoVSn powder after 15 and $30 \mathrm{~h}$ milling, and that of the SPS-consolidated bulk sample prepared from the milled powder mixture that was annealed at $900{ }^{\circ} \mathrm{C}$ for $20 \mathrm{~h}$. The XRD patterns of the SPS-consolidated CoVSn bulk sample revealed the presence 
of three binary intermetallics, namely, $\mathrm{SnV}_{3}, \mathrm{Co}_{2} \mathrm{Sn}$, and $\mathrm{Co}_{3} \mathrm{~V}$, in addition to the non-stoichiometry CoVSn half-Heusler alloy. Therefore, the synthesized compound was shown to be a multi-phase material. Further, the back-scattered electron (BSE) image and the energy dispersive spectroscopy (EDS) maps of the material, as shown in Figure 4, illustrated a heterogeneous microstructure, which agrees with the observation from the XRD analysis. The non-uniform dispersion of $\mathrm{Co}, \mathrm{V}$, and $\mathrm{Sn}$ provide evidence of the presence of a multiphase structure with various micro-clusters.

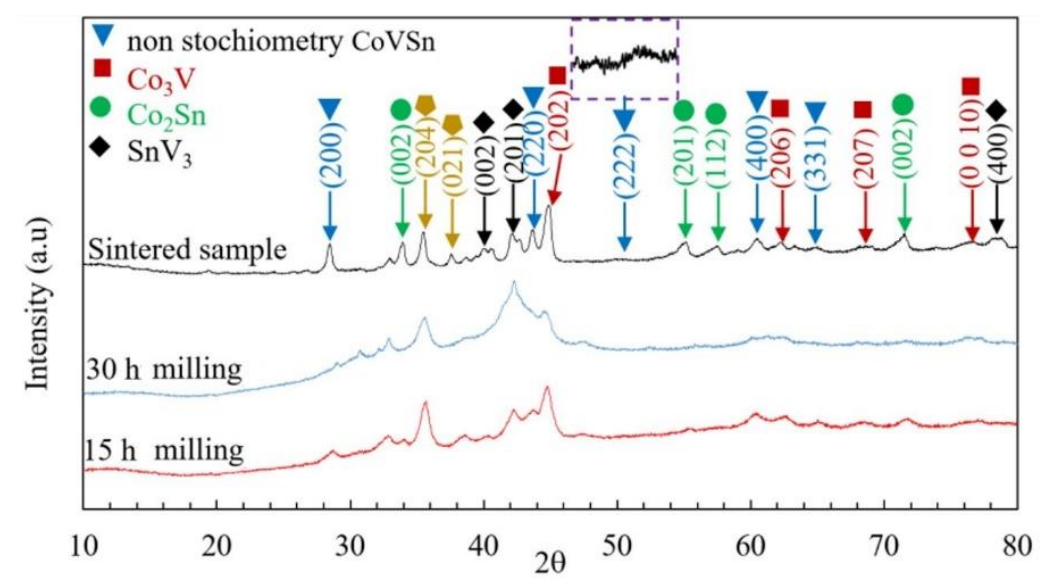

Figure 3. XRD patterns of the synthesized CoVSn compound.

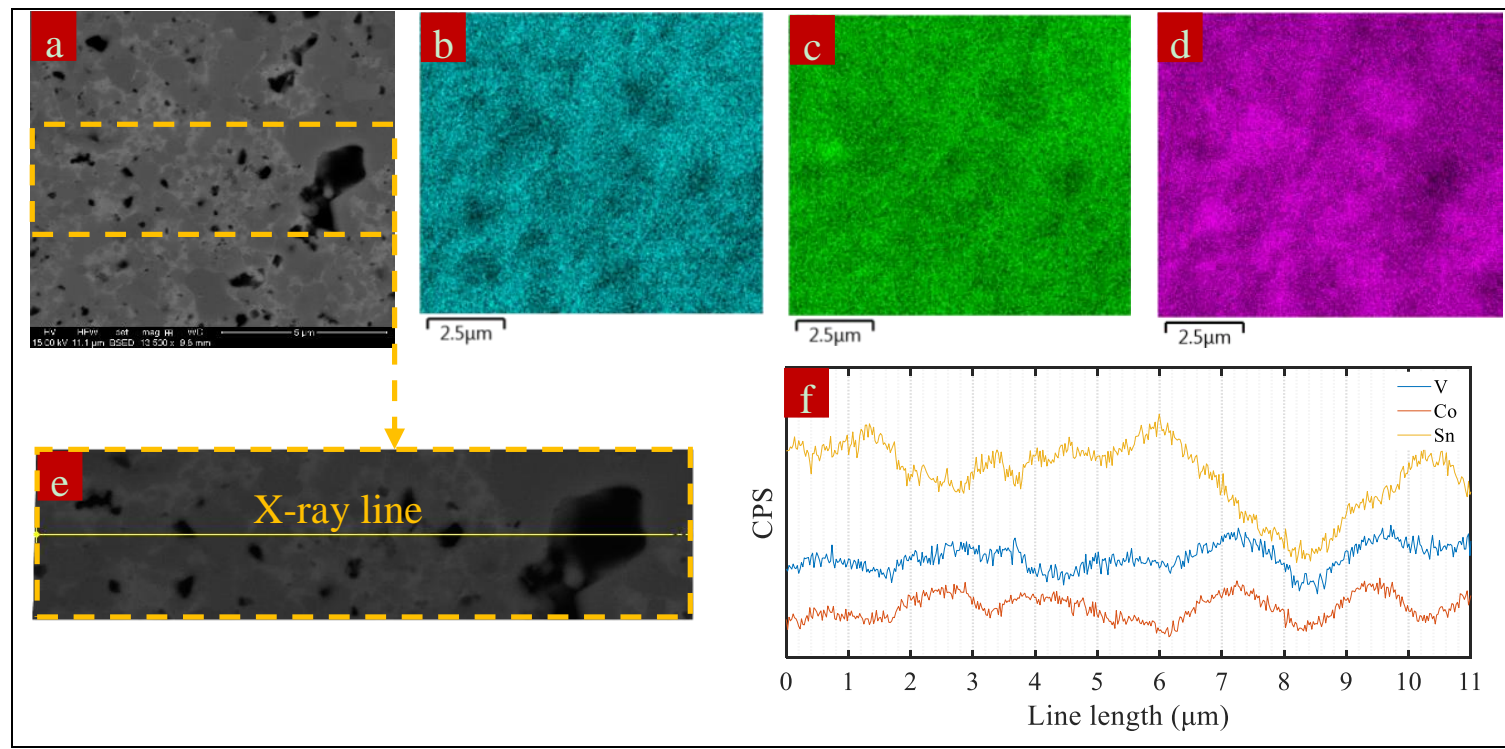

Figure 4. (a) BSE micrograph of the SPS-consolidated CoVSn composition and EDS-maps of (b) Co, (c) V, and (d) Sn. (e) X-ray line scan and (f) element distribution along with the X-ray line scan.

Figure 5 shows the thermoelectric parameters $S, \sigma, k$ (thermal conductivity), and zT of the synthesized compound over a temperature range of 25 to $550{ }^{\circ} \mathrm{C}$. The Seebeck coefficient was negative, indicating an n-type semiconductor. This is in contrast with the theoretical prediction that the CoVSn compound should be a p-type semiconductor $[38,39]$. The physical properties of the Heusler-based compound are generally highly related to the crystallographic order [41]. The observed multiphase structure (Figure 5) combining metallic and semiconductor characteristics due to the presence of intermetallics $\left(\mathrm{SnV}_{3}, \mathrm{Co}_{2} \mathrm{Sn}\right.$, and $\left.\mathrm{Co}_{3} \mathrm{~V}\right)$ and a semiconductor ( $\left.\mathrm{CoVSn}\right)$, respectively. Therefore, the carrier type of the composition cannot be assigned to the single-phase half-Heusler CoVSn compound. 
As illustrated in Figure 4, the multi-phase structure containing various intermetallic compounds with both semiconductor and metallic characteristics provides semiconductor-metal interfaces [42]. The CoVSn compound containing the intermetallic phases has both ionic and covalent bonds. The presence of both ionic and covalent bonds in CoVSn (VSn: ionic-rock salt; CoSn: covalent-Zinc blend) can influence the stability of the semiconductor-metal interfaces (i.e., interface behavior) [43]. The metal-semiconductor contact lines up the chemical potentials and develops a Schottky barrier at the interface that can lead to distinct chemical and electrical properties different from the bulk compounds [44]. It is instructive to look at the thermodynamics of the ternary phase diagram of CoVSn. Such data are not currently available, being a new alloy. Therefore, we calculated the ternary phase diagram of the Co-V-Sn over the temperatures range of interest, 25 to $1200{ }^{\circ} \mathrm{C}$. The Thermo-Calc 2016a package was used for this calculation. Figure 6 shows the ternary phase diagrams at the selected temperatures of $1100,900,600$, and $25^{\circ} \mathrm{C}$.

Table 2. Phase compositions of the nominated areas in Figure 6.

\begin{tabular}{|c|c|c|}
\hline Temperature $\left({ }^{\circ} \mathrm{C}\right)$ & Label & Phase (s) \\
\hline \multirow{9}{*}{25} & $a_{2}$ & $\mathrm{Co}_{3} \mathrm{Sn}_{2} \_\mathrm{A}+\mathrm{HCP} \_\mathrm{A} 3+\mathrm{HCP} \mathrm{ORD}$ \\
\hline & $b_{2}$ & $\mathrm{Co}_{3} \mathrm{Sn}_{2} \_\mathrm{A}+\mathrm{CoSn}+\mathrm{HCP} \_\mathrm{ORD}$ \\
\hline & $\mathrm{c}_{2}$ & $\mathrm{CoSn}+\mathrm{HCP} \_\mathrm{ORD}+\mathrm{Sn}_{3} \mathrm{~V}_{2}$ \\
\hline & $d_{2}$ & $\mathrm{CoSn}+\mathrm{CoSn}_{2}+\mathrm{Sn}_{3} \mathrm{~V}_{2}$ \\
\hline & $\mathrm{e}_{2}$ & $\mathrm{BCT} \_\mathrm{A} 5+\mathrm{CoSn}_{2}+\mathrm{Sn}_{3} \mathrm{~V}_{2}$ \\
\hline & $\mathrm{f}_{2}$ & $\mathrm{HCP} \_\mathrm{ORD}+\mathrm{Sn} 3 \mathrm{~V}_{2}+\mathrm{SnV}_{3}$ \\
\hline & $\mathrm{g}_{2}$ & $\mathrm{CoV}_{3 \_} \mathrm{A} 15+\mathrm{HCP} \_\mathrm{ORD}+\mathrm{SnV}_{3}$ \\
\hline & $\mathrm{h}_{2}$ & BCC_B2 $+\mathrm{CoV}_{3 \_} \mathrm{A} 15+\mathrm{SnV}_{3}$ \\
\hline & $\mathrm{i}_{2}$ & BCC_B2 $+\mathrm{CoV}_{3 \_} \mathrm{A} 15$ \\
\hline \multirow{16}{*}{600} & $a_{6}$ & $\mathrm{Co}_{3} \mathrm{Sn}_{2} \_\mathrm{A}+\mathrm{FCC}_{-} \mathrm{L} 12$ \\
\hline & $\mathrm{b}_{6}$ & $\mathrm{Co}_{3} \mathrm{Sn}_{2} \_\mathrm{B}+\mathrm{FCC} \_\mathrm{L} 12+\mathrm{HCP} \_\mathrm{ORD}$ \\
\hline & $\mathrm{c}_{6}$ & $\mathrm{Co}_{3} \mathrm{Sn}_{2} \_\mathrm{B}+\mathrm{HCP} \_\mathrm{ORD}$ \\
\hline & $\mathrm{d}_{6}$ & $\mathrm{Co}_{3} \mathrm{Sn}_{2}$ B $+\mathrm{CoSn}+\mathrm{HCP}$-ORD \\
\hline & $\mathrm{e}_{6}$ & ALTA_SIGMA $(\mathrm{V}, \mathrm{Co})+\mathrm{CoSn}+\mathrm{HCP} \_\mathrm{ORD}$ \\
\hline & $\mathrm{f}_{6}$ & ALTA_SIGMA $(\mathrm{V}, \mathrm{Co})+\mathrm{CoSn}$ \\
\hline & $g_{6}$ & ALTA_SIGMA(V, Co $)+\operatorname{CoSn}+\mathrm{SnV}_{3}$ \\
\hline & $\mathrm{h}_{6}$ & $\operatorname{CoSn}+\mathrm{Sn}_{3} \mathrm{~V}_{2}+\mathrm{SnV}_{3}$ \\
\hline & $\mathrm{i}_{6}$ & $\mathrm{LIQUID}+\operatorname{CoSn}+\mathrm{Sn}_{3} \mathrm{~V}_{2}$ \\
\hline & $\mathrm{j}_{6}$ & $\mathrm{LIQUID}+\mathrm{Sn}_{3} \mathrm{~V}_{2}$ \\
\hline & $\mathrm{k}_{6}$ & ALTA_SIGMA $(\mathrm{V}, \mathrm{Co})+\mathrm{SnV}_{3}$ \\
\hline & $1_{6}$ & ALTA_SIGMA $(\mathrm{V}, \mathrm{Co})+\mathrm{CoV}_{3 \_} \mathrm{A} 15+\mathrm{SnV}_{3}$ \\
\hline & $\mathrm{h}_{2}$ & $\mathrm{BCC} \_\mathrm{B} 2+\mathrm{CoV}_{3-} \mathrm{A} 15+\mathrm{SnV}_{3}$ \\
\hline & $\mathrm{i}_{2}$ & 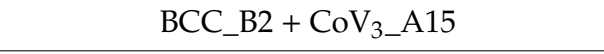 \\
\hline & $\mathrm{O}_{6}$ & BCC_B2 \\
\hline & $\mathrm{p}_{6}$ & $\mathrm{BCC} \_\mathrm{B} 2+\mathrm{SnV}_{3}$ \\
\hline
\end{tabular}


Table 2. Cont.

\begin{tabular}{|c|c|c|}
\hline Temperature $\left({ }^{\circ} \mathrm{C}\right)$ & Label & Phase (s) \\
\hline \multirow{19}{*}{900} & $\mathrm{a}_{9}$ & FCC_L12 \\
\hline & $b_{9}$ & $\mathrm{Co}_{3} \mathrm{Sn}_{2} \_\mathrm{B}+\mathrm{FCC} \_\mathrm{L} 12$ \\
\hline & $\mathrm{C}_{9}$ & $\mathrm{Co}_{3} \mathrm{Sn}_{2} \_\mathrm{B}+\mathrm{FCC} \_\mathrm{L} 12+\mathrm{HCP} \_\mathrm{ORD}$ \\
\hline & $\mathrm{d}_{9}$ & $\mathrm{Co}_{3} \mathrm{Sn}_{2} \_\mathrm{B}+\mathrm{HCP}$ _ORD \\
\hline & $e_{9}$ & ALTA_SIGMA $(\mathrm{V}, \mathrm{Co})+\mathrm{Co}_{3} \mathrm{Sn}_{2} \_\mathrm{B}+\mathrm{HCP}$ ORD \\
\hline & $\mathrm{f}_{9}$ & ALTA_SIGMA(V, Co $)+\mathrm{Co}_{3} \mathrm{Sn}_{2}$ B \\
\hline & $g_{9}$ & $\mathrm{Co}_{3} \mathrm{Sn}_{2} \_\mathrm{B}+\mathrm{BCC} \_\mathrm{B} 2+\mathrm{CoSn}$ \\
\hline & $\mathrm{h}_{9}$ & ALTA_SIGMA(V, Co $)+\mathrm{Co}_{3} \mathrm{Sn}_{2}$ B + BCC_B2 \\
\hline & iq & $\mathrm{BCC} \_\mathrm{B} 2+\mathrm{Co}_{3} \mathrm{Sn}_{2} \_\mathrm{B}$ \\
\hline & j9 & LIQUID + BCC_B2 + CoSn \\
\hline & $\mathrm{k}_{9}$ & ALTA_SIGMA $(\mathrm{V}, \mathrm{Co})+\mathrm{CoV}_{3 \_} \mathrm{A} 15+\mathrm{BCC}$ B2 \\
\hline & $l_{9}$ & BCC_B2 + CoSn \\
\hline & $\mathrm{i}_{2}$ & BCC_B2 + CoV $_{3 \_A 15}$ \\
\hline & $\mathrm{O}_{6}$ & BCC_B2 \\
\hline & $\mathrm{O}_{9}$ & LIQUID + $\mathrm{SnV}_{3}$ \\
\hline & $\mathrm{p}_{9}$ & LIQUID + BCC_B2 + SnV 3 \\
\hline & $\mathrm{p}_{6}$ & BCC_B2 $+\mathrm{SnV}_{3}$ \\
\hline & $\mathrm{r}_{9}$ & LIQUID + BCC_B2 \\
\hline & $\mathrm{S}_{9}$ & ALTA_SIGMA(V, Co) + BCC_B2 \\
\hline \multirow{17}{*}{1100} & $\mathrm{a}_{9}$ & FCC_L12 \\
\hline & $b_{9}$ & $\mathrm{Co}_{3} \mathrm{Sn}_{2} \mathrm{~B}+\mathrm{FCC} \_\mathrm{L} 12$ \\
\hline & $\mathrm{c}_{11}$ & LIQUID + $\mathrm{Co}_{3} \mathrm{Sn}_{2} \_\mathrm{B}+$ FCC_L12 \\
\hline & $\mathrm{d}_{11}$ & LIQUID + FCC_L12 \\
\hline & $\mathrm{e}_{11}$ & LIQUID + ALTA_SIGMA \\
\hline & $\mathrm{f}_{11}$ & LIQUID + ALTA_SIGMA (V, Co) + FCC_L12 \\
\hline & $\mathrm{g}_{11}$ & LIQUID \\
\hline & $\mathrm{h}_{11}$ & LIQUID + ALTA_SIGMA(V,Co) + BCC_B2 \\
\hline & $i_{11}$ & ALTA_SIGMA (V,Co) + BCC_B2 \\
\hline & $\mathrm{O}_{6}$ & BCC_B2 \\
\hline & $\mathrm{p}_{6}$ & $\mathrm{BCC} \_\mathrm{B} 2+\mathrm{SnV}_{3}$ \\
\hline & $l_{11}$ & LIQUID + BCC_B2 \\
\hline & $\mathrm{m}_{11}$ & LIQUID + LIQUID \#2 + SnV 3 \\
\hline & $\mathrm{n}_{11}$ & LIQUID + LIQUID \#2 + BCC_B2 \\
\hline & $l_{11}$ & LIQUID + BCC_B2 \\
\hline & $\mathrm{O}_{9}$ & LIQUID + SnV 3 \\
\hline & $\mathrm{q}_{11}$ & LIQUID + LIQUID \#2 \\
\hline
\end{tabular}




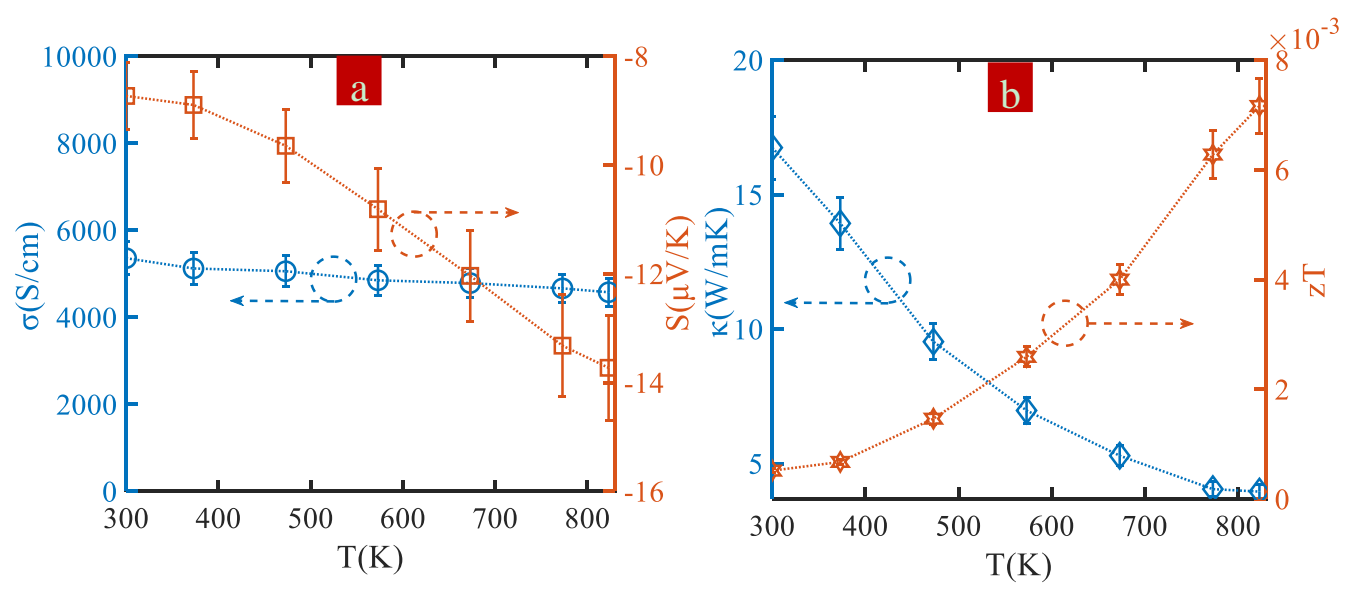

Figure 5. Temperature dependence thermoelectric parameters of CoVSn compounds. (a) electrical conductivity and Seebeck coefficient, (b) Thermal conductivity and zT.
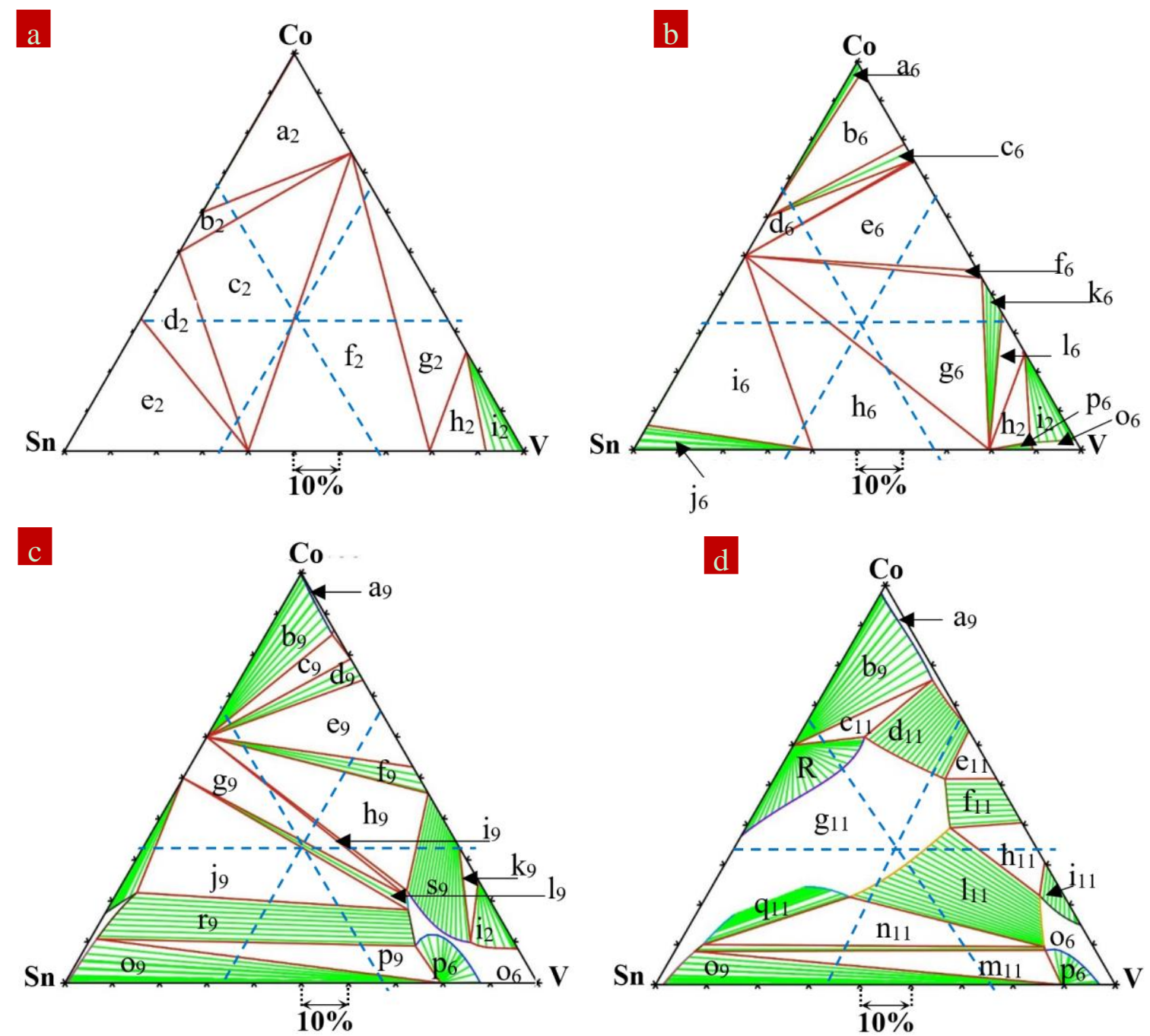

Figure 6. Calculated ternary phase diagrams (atomic ratio) of Co-V-Sn at (a) $25^{\circ} \mathrm{C}$, (b) $600{ }^{\circ} \mathrm{C}$, (c) $900{ }^{\circ} \mathrm{C}$ and (d) $1100{ }^{\circ} \mathrm{C}$. Crossing point showed a composition of 1:1:1 of atomic percent and a weight percent of Co: 26wt.\%, V:22 wt.\% and Sn: 52wt.\%. Thermo-Calc 2016a package was employed to calculate the ternary phase diagrams under the atmospheric pressure. Table 2 give the phase compositions of the nominated areas in Figure 6. 
Table 3 lists the different phases at the center of the phase diagram (i.e., the equal atomic concentration of the elements over 100-degree temperature steps from 25 to $1100{ }^{\circ} \mathrm{C}$ ). These diagrams further confirm that at thermodynamic equilibrium, the material decomposes into multiple phases, as listed in Table 3, which agrees with the observation in the microstructural analysis (Figures 3 and 4).

Table 3. The phase composition of CoVSn compound (1:1:1) at the temperature of 25 to $1100{ }^{\circ} \mathrm{C}$.

\begin{tabular}{|c|c|}
\hline $\mathrm{T}\left({ }^{\circ} \mathrm{C}\right)$ & Phase/Crystal Structure/Elements \\
\hline 25 & $\mathrm{CoSn}, \mathrm{HCP} \_\mathrm{ORD}(\mathrm{Co}, \mathrm{V})$ and $\mathrm{Sn}_{3} \mathrm{~V}_{2}$ \\
\hline 100 & $\mathrm{SnV}_{3}, \mathrm{HCP} \_\mathrm{ORD}(\mathrm{Co}, \mathrm{V})$ and $\mathrm{Sn}_{3} \mathrm{~V}_{2}$ \\
\hline 200 & $\mathrm{SnV}_{3}, \mathrm{HCP} \_\mathrm{ORD}(\mathrm{Co}, \mathrm{V})$ and $\mathrm{Sn}_{3} \mathrm{~V}_{2}$ \\
\hline 300 & CoSn, HCP_ORD $(\mathrm{Co}, \mathrm{V})$ and $\mathrm{Sn}_{3} \mathrm{~V}_{2}$ \\
\hline 400 & CoSn, HCP_ORD $(\mathrm{Co}, \mathrm{V})$ and $\mathrm{Sn}_{3} \mathrm{~V}_{2}$ \\
\hline 500 & CoSn, HCP_ORD $(\mathrm{Co}, \mathrm{V})$ and $\mathrm{Sn}_{3} \mathrm{~V}_{2}$ \\
\hline 600 & CoSn, SnV 3 , ALTA_SIGMA (V, CO) \\
\hline 700 & $\mathrm{SnV}_{3}, \mathrm{BCC}$ _B2 (Co,V,Sn), ALTA_SIGMA (V, Co) \\
\hline 800 & $\begin{array}{l}\text { Equilibrium line between two areas of }\left(\mathrm{CoSn}, \mathrm{BCC} \_\mathrm{B} 2(\mathrm{Co}, \mathrm{V}, \mathrm{Sn})\right) \text { and } \\
\text { (ALTA_SIGMA }(\mathrm{V}, \mathrm{Co}), \mathrm{CoSn}, \mathrm{BCC} B \mathrm{~B} 2(\mathrm{Co}, \mathrm{V}, \mathrm{Sn}))\end{array}$ \\
\hline 900 & $\begin{array}{l}\text { Equilibrium line between two areas of }\left(\mathrm{CoSn}, \mathrm{BCC} \_\mathrm{B} 2(\mathrm{Co}, \mathrm{V}, \mathrm{Sn})\right) \text { and } \\
\text { (LIQUID, CoSn, BCC_B2 }(\mathrm{Co}, \mathrm{V}, \mathrm{Sn}))\end{array}$ \\
\hline 1000 & LIQUID, BCC_B2 (Co,V,Sn) \\
\hline 1100 & LIQUID \\
\hline
\end{tabular}

As shown in Table 3, there is no single phase of CoVSn, but mainly binary compounds of $\mathrm{CoSn}, \mathrm{SnV}_{3}, \mathrm{Co}_{3} \mathrm{~V}$, and $\mathrm{Sn}_{2} \mathrm{~V}_{3}$. Our observation of the multiphase structure, containing three binary intermetallics, contradicts previous studies [38,45]. In the theoretical analysis of this composition (1:1:1) [45], the calculated phase diagram showed a specific area for the stable CoVSn compound. However, the presence of this single-phase alloy was not experimentally confirmed.

\section{Conclusions}

The single-phase half-Heusler CoVSn was predicted theoretically as a stable thermodynamic material with prospective properties for spintronics and thermoelectric applications, although it was never experimentally confirmed. According to the theoretical and experimental data presented here, the CoVSn phase was found to be thermodynamically unstable, and its partial decomposition into metallic phases is unavoidable at the equilibrium state. In this study, the experimental realization of the CoVSn compound with a heterogeneous microstructure was represented. The material analysis showed the presence of the half-Heusler ternary alloy of non-stoichiometry CoVSn as the semiconductor phase, mixed with three binary intermetallics: $\mathrm{SnV}_{3}, \mathrm{Co}_{2} \mathrm{Sn}$, and $\mathrm{Co}_{3} \mathrm{~V}$. The combination of X-ray diffraction, energy-dispersive $X$-ray spectroscopy, and transport properties confirmed the formation of the composite structure. The composite material demonstrated a metallic electronic behavior with a degenerate carrier concentration.

Author Contributions: Conceptualization, S.H.Z., R.G., and D.V.; Methodology, S.H.Z., R.G., and D.V.; Validation, S.H.Z., R.G., and D.V.; Formal Analysis, S.H.Z.; Investigation, S.H.Z.; Resources, S.H.Z.; Data Curation, S.H.Z.; Writing-Original Draft Preparation, S.H.Z.; Writing-Review \& Editing, S.H.Z., R.G., and D.V.; Visualization, S.H.Z., A.D., S.H.; Supervision, R.G., and D.V.; Project Administration, S.H.Z.; Funding Acquisition, R.G., D.V.and S.H. All authors have read and agreed to the published version of the manuscript.

Funding: This research was funded by the Australian Government Research Training Program Scholarship and The ARC Graphene Enabled Industry Transformation Hub at the University of Adelaide. Also, this study is partially based upon work supported by the AFOSR under contract number FA9550-12-1-0225 and the NSF under grant numbers ECCS-1351533, ECCS-1515005, and ECCS-1711253. Moreover, this research is partly supported by 
the Basic Research Laboratory Program through the Ministry of Education of the Republic of Korea under grant number 2019R1A4A1026125.

Acknowledgments: Electron microscopy was carried out at the Adelaide Microscopy, University of Adelaide.

Conflicts of Interest: There is no conflict to declare.

\section{References}

1. Shafai, C. Optimization of $\mathrm{Bi}_{2} \mathrm{Te}_{3}$ thin films for microintegrated Peltier heat pumps. J. Vac. Sci. Technol. A 1997, 15, 2798-2801. [CrossRef]

2. Scoville, A.N.; Bajgar, C.; Vandersande, J.; Fleurial, J. High figure-of-merit n-type SiGe/GaP alloys, IECEC 91. In Proceedings of the 26th Intersociety Energy Conversion Engineering Conference, Boston, MA, USA, 4-9 August 1991; American Nuclear Society: La Grange Park, IL, USA, 1991; pp. 224-229.

3. Snyder, G.J.; Toberer, E.S. Complex thermoelectric materials. Nat. Mater. 2008, 7, 105-114. [CrossRef] [PubMed]

4. Beretta, D.; Neophytou, N.; Hodges, J.M.; Kanatzidis, M.G.; Narducci, D.; Martín-González, M.S.; Beekman, M.; Balke, B.; Cerretti, G.; Tremel, W.; et al. Thermoelectrics: From history, a window to the future. Mater. Sci. Eng. R: Rep. 2019, 138, 100501. [CrossRef]

5. Hermann, R.P.; Jin, R.; Schweika, W.; Grandjean, F.; Mandrus, D.G.; Sales, B.C.; Long, G.J. Einstein Oscillators in Thallium Filled Antimony Skutterudites. Phys. Rev. Lett. 2003, 90, 135505. [CrossRef]

6. Bentien, A.; Christensen, M.; Bryan, J.D.; Sanchez, A.; Paschen, S.; Steglich, F.; Stucky, G.D.; Iversen, B.B. Thermal conductivity of thermoelectric clathrates. Phys. Rev. B 2004, 69, 045107. [CrossRef]

7. Anand, S.; Wood, M.; Wolverton, C.; Snyder, G.J. An Enormous Class of Double Half-Heusler Compounds with Low Thermal Conductivity; Cornell University: Ithaca, NY, USA, 2019.

8. Jain, A.; Shin, Y.; Persson, K.A. Computational predictions of energy materials using density functional theory. Nat. Rev. Mater. 2016, 1, 15004. [CrossRef]

9. Fu, C.; Bai, S.; Liu, Y.; Tang, Y.; Chen, L.; Zhao, X.; Zhu, T. Realizing high figure of merit in heavy-band p-type half-Heusler thermoelectric materials. Nat. Commun. 2015, 6, 8144. [CrossRef]

10. Galanakis, I. Theory of Heusler and Full-Heusler Compounds; Springer: Cham, Switzerland, 2015; Volume 222, pp. 3-36.

11. Shutohs, S.S.N. Thermoelectric properties of the TiX (Zr0.5Hf0.5)1-XNiSn half-Heusler compounds. J. Alloys Compd. 2005, 389, 204-208. [CrossRef]

12. Huang, L.; He, R.; Chen, S.; Zhang, H.; Dahal, K.; Zhou, H.; Wang, H.; Zhang, Q.; Ren, Z. A new n-type half-Heusler thermoelectric material NbCoSb. Mater. Res. Bull. 2015, 70, 773-778. [CrossRef]

13. Zhou, M.; Feng, C.; Chen, L.; Huang, X. Effects of partial substitution of Co by Ni on the high-temperature thermoelectric properties of TiCoSb-based half-Heusler compounds. J. Alloys Compd. 2005, 391, $194-197$. [CrossRef]

14. Chai, Y.W.; Oniki, T.; Kimura, Y. Microstructure and thermoelectric properties of a ZrNi1.1Sn half-Heusler alloy. Acta Mater. 2015, 85, 290-300. [CrossRef]

15. Sakurada, S.; Shutoh, N. Effect of Ti substitution on the thermoelectric properties of (Zr,Hf) NiSn half-Heusler compounds. Appl. Phys. Lett. 2005, 86, 82105. [CrossRef]

16. Misra, D.K.; Rajput, A.; Bhardwaj, A.; Chauhan, N.S.; Singh, S. Enhanced power factor and reduced thermal conductivity of a half-Heusler derivative Ti9Ni7Sn8: A bulk nanocomposite thermoelectric material. Appl. Phys. Lett. 2015, 106, 103901. [CrossRef]

17. Lee, P.-J.; Chao, L.-S. High-temperature thermoelectric properties of Ti0.5 (ZrHf) 0.5-xNbxNi0.9Pd0.1Sn0.98Sb0.02 half-Heusler alloys. J. Alloys Compd. 2010, 504, 192-196. [CrossRef]

18. Zhang, H.; Wang, Y.; Huang, L.; Chen, S.; Dahal, H.; Wang, D.; Ren, Z. Synthesis and thermoelectric properties of n-type half-Heusler compound VCoSb with valence electron count of 19. J. Alloys Compd. 2016, 654, 321-326. [CrossRef]

19. Katsuyama, S.; Kobayashi, T. Effect of mechanical milling on thermoelectric properties of half-Heusler ZrNiSn0.98Sb0.02 intermetallic compound. Mater. Sci. Eng. B 2010, 166, 99-103. [CrossRef]

20. Gürth, M.; Rogl, G.; Romaka, V.V.; Grytsiv, A.; Bauer, E.; Rogls, P. Thermoelectric high ZT half-Heusler alloys Ti 1-x-y Zr x Hf y NiSn $(0 \leq x \leq 1 ; 0 \leq y \leq 1)$. Acta Mater. 2016, 104, 210-222. [CrossRef] 
21. Zhu, T.J.; Xiao, K.; Yu, C.; Shen, J.J.; Yang, S.H.; Zhou, A.J.; Zhao, X.B.; He, J. Effects of yttrium doping on the thermoelectric properties of Hf $0.6 \mathrm{Zr} 0.4 \mathrm{NiSn} 0.98 \mathrm{Sb} 0.02$ half-Heusler alloys. J. Appl. Phys. 2010, $108,044903$.

22. Zhang, H.; Wang, Y.; Dahal, K.; Mao, J.; Huang, L.; Zhang, Q.; Ren, Z. Thermoelectric properties of n-type half-Heusler compounds (Hf0.25Zr0.75)1-Nb NiSn. Acta Mater. 2016, 113, 41-47. [CrossRef]

23. Joshi, G.; Yan, X.; Wang, H.; Liu, W.; Chen, G.; Ren, Z. Enhancement in Thermoelectric Figure-Of-Merit of an N-Type Half-Heusler Compound by the Nanocomposite Approach. Adv. Energy Mater. 2011, 1, $643-647$. [CrossRef]

24. Berry, T.; Fu, C.; Auffermann, G.; Fecher, G.H.; Schnelle, W.; Serrano-Sanchez, F.; Yue, Y.; Liang, H.; Felser, C. Enhancing Thermoelectric Performance of TiNiSn Half-Heusler Compounds via Modulation Doping. Chem. Mater. 2017, 29, 7042-7048. [CrossRef]

25. Hazama, H.; Matsubara, M.; Asahi, R. Thermoelectric Properties of Off-Stoichiometric Ti-Ni-Sn Half-Heusler Systems. J. Electron. Mater. 2012, 41, 1730-1734. [CrossRef]

26. Huang, L.; Zhang, Q.; Wang, Y.; He, R.; Shuai, J.; Zhang, J.; Wang, C.; Ren, Z. The effect of Sn doping on thermoelectric performance of n-type half-Heusler NbCoSb. Phys. Chem. Chem. Phys. 2017, 19, 25683-25690. [CrossRef] [PubMed]

27. Rausch, E.; Balke, B.; Ouardi, S.; Felser, C. Enhanced thermoelectric performance in the p-type half-Heusler (Ti/Zr/Hf)CoSb0.8Sn0.2 system via phase separation. Phys. Chem. Chem. Phys. 2014, 16, 25258-25262. [CrossRef] [PubMed]

28. He, R.; Zhu, H.; Sun, J.; Mao, J.; Reith, H.; Chen, S.; Schierning, G.; Nielsch, K.; Ren, Z. Improved thermoelectric performance of n-type half-Heusler MCo1-xNixSb (M = Hf, Zr). Mater. Today Phys. 2017, 1, 24-30. [CrossRef]

29. Gałązka, K.; Populoh, S.; Xie, W.; Yoon, S.; Saucke, G.; Hulliger, J.; Weidenkaff, A.; Büttner, G. Improved thermoelectric performance of (Zr0.3Hf0.7)NiSn half-Heusler compounds by Ta substitution. J. Appl. Phys. 2014, 115, 183704.

30. Zhao, D.; Zuo, M.; Bo, L.; Wang, Y. Synthesis and Thermoelectric Properties of Pd-Doped ZrCoBi Half-Heusler Compounds. Materials 2018, 11, 728. [CrossRef]

31. Geng, H.; Zhang, H. Effects of phase separation on the thermoelectric properties of (Ti, Zr, Hf) NiSn half-Heusler alloys. J. Appl. Phys. 2014, 116, 33708. [CrossRef]

32. Tang, Y.; Li, X.; Martin, L.H.J.; Ivas, T.; Leinenbach, C.; Anand, S.; Peters, M.; Snyder, G.J.; Battaglia, C.; Cuervo-Reyes, E. Impact of Ni content on the thermoelectric properties of half-Heusler TiNiSn. Energy Environ. Sci. 2018, 11, 311-320. [CrossRef]

33. Xie, H.; Wang, H.; Fu, C.; Liu, Y.; Snyder, G.J.; Zhao, X.; Zhu, T. The intrinsic disorder related alloy scattering in ZrNiSn half-Heusler thermoelectric materials. Sci. Rep. 2014, 4, 6888. [CrossRef]

34. Xia, K.; Liu, Y.; Anand, S.; Snyder, G.J.; Xin, J.; Yu, J.; Zhao, X.; Zhus, T. Enhanced Thermoelectric Performance in 18-Electron Nb0.8CoSb Half-Heusler Compound with Intrinsic Nb Vacancies. Adv. Funct. Mater. 2018, 28, 1705845. [CrossRef]

35. Zeeshan, M.; Brink, J.V.D.; Kandpal, H.C. Hole-doped cobalt-based Heusler phases as prospective high-performance high-temperature thermoelectrics. Phys. Rev. Mater. 2017, 1, 74401. [CrossRef]

36. Öğ̈̈t, S.; Rabe, K.M. Band gap and stability in the ternary intermetallic compounds NiSn M (M= Ti, Zr, Hf): A first-principles study. Phys. Rev. B 1995, 51, 10443-10453. [CrossRef] [PubMed]

37. Hichour, M.; Rached, D.; Khenata, R.; Rabah, M.; Merabet, M.; Reshak, A.; Bin-Omran, S.; Ahmed, R. Theoretical investigations of NiTiSn and CoVSn compounds. J. Phys. Chem. Solids 2012, 73, 975-981. [CrossRef]

38. Shi, H.; Ming, W.; Parker, D.S.; Du, M.H.; Singh, D.J. Prospective high thermoelectric performance of the heavily p-doped half-Heusler compound CoVSn. Phys. Rev. B 2017, 95, 195207. [CrossRef]

39. Zeeshan, M.; Singh, H.K.; Brink, J.V.D.; Kandpal, H.C. Ab initio design of new cobalt-based half-Heusler materials for thermoelectric applications. Phys. Rev. Mater. 2017, 1, 075407. [CrossRef]

40. Schroeder, D.V.; Gould, H. An Introduction to Thermal Physics; Addison-Wesley: Reading, MA, USA, 2000; pp. 149-220.

41. Tobola, J.; Kaprzyk, S.; Skolozdra, R.V.; A Kouacou, M.; Pierre, J. Crossover from semiconductor to magnetic metal in semi-Heusler phases as a function of valence electron concentration. J. Phys.: Condens. Matter 1998, 10, 1013-1032. [CrossRef]

42. Villars, P. Inorganic Solid Phases, Springer Materials (Online Database); Springer: Heidelberg, Germany, 2016. 
43. Brillson, L. Metal-semiconductor interfaces. Surf. Sci. 1994, 299, 909-927. [CrossRef]

44. Batra, I.; Tekman, E.; Ciraci, S. Theory of Schottky barrier and metallization. Prog. Surf. Sci. 1991, 36, $289-361$. [CrossRef]

45. Lue, C.; Öner, Y.; Naugle, D.; Ross, J.J.H. Magnetism of new semi-Heusler compounds FeVSn and CoVSn. IEEE Trans. Magn. 2001, 37, 2138-2140. [CrossRef] 